REVISTA X, Curitiba, volume 13, n.2,p.93-110, 2018.

\title{
O REALISMO FORMAL NA AULA DE LÍNGUA ESTRANGEIRA
}

Realism in the Foreign Language Class

\section{Letícia Pilger da SILVA (UFPR) ${ }^{1}$}

RESUMO: Este artigo pretende realizar uma análise teórico-prática da verossimilhança no ensino de língua estrangeira na relação professor-aluno e aluno-livro didático, na concepção de língua e cultura, e na construção dos personagens de materiais didáticos a partir da aproximação da aula de língua estrangeira com os componentes "realismo formal" e "personagens" do gênero literário romance. Para tal, serão utilizados textos sobre realismo formal no romance, gênese de personagens literários, análise de material didático de língua estrangeira, e os pressupostos bakhtinianos de dialogismo, polifonia e exotopia. A partir da discussão teórica, foi realizada uma análise da construção dos personagens de dois materiais didáticos de língua inglesa a fim de investigar a verossimilhança de sua representação e, consequentemente, da concepção de cultura. Como resultado, percebeu-se que a apresentação de personagens verossímeis no livro didático impede uma visão estereotipada e achatada da cultura estrangeira e dinamiza um diálogo intercultural entre a língua materna do aluno e a língua estrangeira.

PALAVRAS-CHAVE: realismo formal; linguística aplicada; material didático.

ABSTRACT: This paper aims to draw a theoretical-practical analysis on verisimilitude in the process of learning-teaching a foreign language in the relationships between teacher-student and student-textbook, the understanding of language and culture, and the creation of fictional characters of textbooks by approaching foreign language teaching the elements "realism" and characters" of the literary genre "novel". For this purpose, this study will discuss texts on realism in novels, the conception of literary characters, analysis of textbooks of foreign language, and the Bakhtinian concepts of dialogism, polyphony and exotopy. From this theoretical discussion, it is drawn an analysis of the representation of the characters from two English language textbooks aiming to investigate the verisimilitude of their representation and, consequently, of the conception of culture. As a result, it was realized that the credible characters in textbooks impedes a stereotyped perception of the foreign culture and potentializes an intercultural dialogue between the student's native language and the foreign language.

KEYWORDS: formal realism; applied linguistics; textbook.

\section{INTRODUÇÃO}

Pretendemos, neste presente artigo, traçar um paralelo entre dois constituintes do gênero literário romance - personagens e realismo formal - e a aula de língua estrangeira e seus elementos: aluno, professor, sala de aula, língua e livro didático, de

\footnotetext{
${ }^{1}$ Mestranda do programa de Pós-graduação em Letras da Universidade Federal do Paraná (UFPR).
} 
modo a dialogar com duas áreas do curso de Letras: os estudos literários e a linguística aplicada (mais especificamente o ensino de metodologia de línguas estrangeiras). Nosso objetivo é aproximar a aula de língua estrangeira e o romance para investigar a dinâmica ficcional presente na aprendizagem da língua estrangeira, considerando que "existe diálogo entre o universo artístico e a vida extraliterária" (JANZEN, 2010, p. 214) e que também existe diálogo entre o universo da sala de aula e da vida extraclasse. Com base nos pressupostos bakhtinianos de polifonia, exotopia e dialogismo (BAKHTIN, 1997, 2006, 2010), analisaremos a relação professor-aluno e aluno-livro didático, a concepção de língua e a construção dos personagens de dois materiais didáticos. Em suma, pretendemos investigar a verossimilhança da dinâmica na aprendizagem de língua estrangeira, isto é, se os personagens veiculados nos livros didáticos aparentam ser reais e representar a cultural estrangeira, ou se são estereotipados e apresentam identidade achatada.

\section{O ROMANCE, SEUS PERSONAGENS E O REALISMO FORMAL}

O romance é um gênero literário que se consagrou no século XVIII com a ascensão da burguesia e com a consequente valorização do indivíduo e da vida privada. O romance é caracterizado por Ian Watt, que pesquisa o romance inglês do século XIX, como um retrato da vida privada que pretende realizar "um relato autêntico das verdadeiras experiências individuais" (WATT, 1990, p. 27). Por isso, podemos dizer que o romancista precisa dar fidelidade à experiência humana, isto é, verossimilhança, a qual é realizada a partir do método narrativo conhecido como realismo formal. $\mathrm{O}$ realismo formal é, nas palavras de Ian Watt (1990, p. 31), “(...) a premissa, ou convenção básica, de que o romance constitui um relato completo e autêntico da experiência humana e, portanto, tem a obrigação de fornecer ao leitor detalhes da história como a individualidade dos agentes envolvidos, os particulares das épocas e locais de suas ações", isto é, verossimilhança. Como o objetivo do romance é imitar/representar a vida humana dentro da sua individualidade, por meio do realismo formal, seus personagens são seres individualizados e específicos, com nome e sobrenome, que habitam espaço e tempo particularizados.

Nós, enquanto leitores, lemos e conseguimos relacionar esses elementos com a "vida real" - mesmo que sejam ficção -, tomando os personagens como "seres possíveis" que vivem vidas que parecem "reais", embora sejam vidas literárias inscritas em palavras. Podemos dizer que o romance é o real ficcionalizado, e o realismo formal 
concede ao texto verossimilhança com a realidade. Dessa forma, "o enredo [do romance] envolveria pessoas específicas em circunstâncias específicas, e não, como fora no passado, tipos humanos genéricos atuando num cenário basicamente determinado pela convenção literária adequada" (WATT, 1990, p. 17). Como disse Candido (1976), o enredo vive por meio das personagens, e estas vivem o enredo, de modo que personagens e enredo estão indissociáveis no texto.

Segundo Antonio Candido (1976), o personagem do romance pode ser uma transposição de modelos ou uma completa invenção, e pode ser construído pela recuperação de outros personagens, ou de pessoas reais que o romancista conhece, ou ainda da combinação de vários personagens ou de várias características de pessoas reais. Fato é que o personagem do romance - homo fictus -, segundo Edward Morgan Foster (apud CANDIDO, 1976), deve lembrar seres vivos de forma a manter relação com a realidade $^{2}$ e com o que se conhece da vida, do homo sapiens.

Os personagens do romance, dentro de sua representação fragmentária, dormem e comem pouco, mas vivem muitas situações (CANDIDO, 1976). Inclusive, ao imitarem a vida, podemos especular sobre o fato de que alguns personagens também são leitores de romance e se relacionam com personagens ficcionais dentro de sua ficcionalidade. Em Dom Quixote, de Miguel de Cervantes, o protagonista lê romances de cavalaria e a imersão é tão grande que estes romances dão acabamento ao protagonista de forma que ele imagina ser um cavalheiro. Em Madame Bovary, de Gustave Flaubert, Emma gostaria de viver a vida das personagens dos livros que lê, e tenta transpor a vida burguesa das personagens para a sua própria vida. Ambos queriam trazer a vida ficcional, a vida criada pela imaginação, para a realidade de suas vidas (que já eram ficcionais). Isto é, assim como os personagens do romance imitam a realidade, os leitores apreendem a realidade e experienciam diferentes modos de existir no mundo (KUNDERA, 2009) através dos romances que leem em um processo dialógico com as diversas vozes que perpassam o livro.

As relações homo sapiens-romance e homo fictus-romance revelam o conceito bakhtiniano de exotopia ${ }^{3}$, que pode ser definido como o fato de que só um Outro ${ }^{4}$ pode dar acabamento a um determinado indivíduo dentro do espaço-tempo. Cristovão Tezza,

\footnotetext{
${ }^{2}$ Mesmo que o romance seja enquadrado na ficção científica, o enredo e os personagens precisam ser críveis para a lógica daquele universo, com aquele mundo possível.

${ }^{3}$ Criado por Bakhtin acerca de reflexões literárias sobre Dostoievski e posteriormente deslocado para discussões mais amplas envolvendo cultura (JANZEN, 2012).
} 
sobre a exotopia bakthiniana, diz que um indivíduo só pode se imaginar sob o olhar de outro, pois "cada um de nós, daqui onde estamos, temos sempre um horizonte; estamos na fronteira do mundo em que vivemos - e só o outro pode nos dar um ambiente, completar o que desgraçadamente falta ao nosso próprio olhar" (TEZZA, 2001, s./p.). Podemos dizer, então, que a personagem do romance é um ser individual perpassado por diversas vozes, seja a do autor; da cultura em que está inserido; seja da cultura e do contexto do leitor, que irá relacionar as diversas vozes e perspectivas presentes no texto durante a leitura ${ }^{5}$; ou dos demais personagens com quem ele interagirá no enredo, revelando a polifonia presente no texto (BAKHTIN, 1997).

Nessa perspectiva dialógica, a palavra de um indivíduo e todo enunciado estão contaminados pelo olhar de fora, do outro que lhe dá acabamento à sua incompletude $a$ priori (TEZZA, 2001), pois este Outro, pelo seu excedente de visão, percebe coisas que são inacessíveis para o indivíduo sobre si mesmo e sua cultura. Para Bakhtin, nenhuma voz fala sozinha e o Outro não é um objeto, mas também sujeito, e está vivo e independente. A perspectiva exotópica permite que o indivíduo veja o mundo a partir da visão e dos valores (que não coincidem com os valores do indivíduo) do Outro. Falar deste Outro é dar voz a ele.

A exotopia, contudo, não consiste na duplicação do Outro e de seus valores, pois “é preferível que ele [o Outro] permaneça fora de mim, pois é a partir da sua posição que pode ver e saber o que, a partir da minha posição, não posso nem ver nem saber, sendo assim que ele poderá enriquecer o acontecimento da minha vida." (BAKHTIN, 1997, p.103). Depois do movimento exotópico e dialógico do olhar do Outro, quando o indivíduo retorna à sua posição inicial, tomando distância do Outro, ele pode retomar a sua incompletude e reformulá-la a partir do "acabamento" que o Outro lhe permitiu (TEZZA, 2001), repensando a si e sua cultura.

\section{OS PERSONAGENS DA SALA DE AULA}

A partir da reflexão teórica acima realizada acerca desses dois elementos do romance - realismo formal e personagens - realizaremos agora uma especulação/reflexão teórico-prática tomando a sala de aula de língua estrangeira como

\footnotetext{
${ }^{4}$ Grafei Outro com letra maiúscula não para defini-lo, mas para inscrevê-lo na posição de sujeito que dá contornos e que dialoga com o indivíduo.

${ }^{5}$ Como defende Wolfgang Iser (1996) acerca do papel do leitor considerando a Estética da Recepção.
} 
REVISTA X, Curitiba, volume 13, n.2,p.93-110, 2018.

um romance onde o uso da língua é estabelecido dentro de um espaço-tempo na relação de dois níveis de personagens, nas quais podemos observar dialogismo e exotopia.

O primeiro nível são os professores e os alunos, indivíduos com nome, sobrenome, história própria e inscritos na cultura e na História. Eles se relacionam dentro do espaço da sala de aula e dentro de um período de tempo determinado, isto é, espaço e tempo particularizados, e constroem juntos conhecimento sobre a outra língua e cultura - considerando que língua e cultura são indissociáveis - e, consequentemente, sobre sua própria cultura materna. A relação entre professor e aluno é exotópica ao possibilitar um diálogo entre ambos os sujeitos na construção do conhecimento, um dando acabamento linguístico-cultural ao outro - já que o discente aprende com o docente e o docente aprende com o discente (FREIRE, 1996).

A interação entre ambos os sujeitos é importante dentro da dinâmica da sala de aula e fundamental para o estabelecimento de verossimilhança e realismo no uso da língua-viva-discurso no espaço-tempo que é a aula. Em alguns contextos de abordagem metodológica tradicional, o professor toma as "rédeas", como se fosse um autor ou narrador tradicional do romance, e guia os alunos, "transferindo-lhes" as estruturas linguísticas de forma regrada e fragmentada e tirando o papel ativo do aluno na construção do conhecimento, transformando-o, assim, em personagem raso e passivo; e também bloqueando a voz do aluno e, consequentemente, a polifonia dentro da sala de aula, o que configura uma perspectiva monológica.

O segundo nível corresponde aos personagens que ilustram os livros/materiais didáticos e guiam os alunos por entre as páginas contando sobre sua vida privada e sobre a sua cultura estrangeira. Eles constituem uma representação do estrangeiro na cultura materna do aluno, assim como a própria visão do estrangeiro criada pelo estudante da língua estrangeira. Vejamos então como estes dois níveis de personagens da sala de aula de língua estrangeira tornam a língua verossímil e se relacionam com o realismo formal.

O realismo formal perpassa a relação entre professor e alunos em termos da concepção de língua utilizada e almejada em aula, e o vínculo entre os dois níveis de personagens - homo sapiens da sala de aula e homo fictus do livro didático - em relação à aceitação daquelas personagens fictícias dos livros didáticos enquanto representantes do nativo da cultura da outra língua. Para investigar como se dá (ou se perde, devido à estereotipização) realismo formal na sala de aula de língua estrangeira, apresentaremos brevemente a visão de língua e cultura para duas abordagens: tradicional e intercultural. 
REVISTA X, Curitiba, volume 13, n.2, p.93-110, 2018.

A visão tradicional de cultura se estrutura na "homogeneização social, fundamentação étnica e delimitação cultural” (JANZEN, 2010, p. 216), revelando apagamento de diferenças socioculturais, negação dos valores do outro e ausência de outras vozes sociais na tentativa de eliminar o estranho/estrangeiro. Ainda na visão tradicional, a língua é vista como expressão da literatura, e língua e cultura são dissociadas. O papel do aluno, nesta abordagem, é conhecer a língua do outro para entendê-la e ter bom desempenho no uso da língua estrangeira, isto é, um aprendizado sobre fatos a fim de tentar se passar pelo Outro (GIMENEZ, 2001). O ensino é majoritariamente expositivo e formal, o que não permite que haja um diálogo entre os seus elementos, como acontece entre leitor-personagem, leitor-autor. Assim, nunca se realiza diálogo intercultural a partir da sua cultura materna, pois o objetivo é compreender e imitar o outro.

A homogeneização cultural, que parte de visão patriarcal e etnocêntrica, pode ser ilustrada pela construção das personagens dos livros didáticos inscritos na abordagem tradicional e estruturalista, que, em sua maioria, são tipificados, estereotipados, apresentados de forma idealizada e com papéis previsíveis (JANZEN, 2012). Apesar de almejarem a representação do real ficcionalizado da vida do nativo e da cultura estrangeira no espaço do livro didático, considerando que os personagens têm nome, fazem parte de uma família e frequentam locais privados, a vida dos personagens é desconectada do contexto histórico em que estão inseridos e não enfrentam muitos problemas no decorrer das unidades.

Dessa forma, esses personagens são monofônicos, isto é, apresentam apenas uma voz, uma faceta da cultura estrangeira, que corresponde majoritariamente à visão patriarcal do mundo cuja representação é guiada por um discurso-mestre etnocêntrico (JANZEN, 2010). Considerando os tipos de personagens propostos por Foster (apud CANDIDO, 1976), esses personagens podem ser considerados planos por não apresentarem profundidade psicológica e não serem perpassados por várias vozes. Há, segundo Henrique Janzen (2012), no personagem inscrito nessa concepção de ensino, a duplicação da visão dos autores do livro didático - o author team (JANZEN, 2012) -, que, por sua vez, estão inseridos não apenas em uma proposta metodológica, mas também em um sistema ideológico que trabalha a favor da representação de valores e grupos determinados.

A tendência nesta abordagem, segundo as análises de livros didáticos tradicionais de alemão realizadas por Henrique Janzen (2008; 2010), são personagens 
REVISTA X, Curitiba, volume 13, n.2,p.93-110, 2018.

integrantes de uma família que segue a versão estereotipadas da típica "família propaganda de margarina”. A mãe é uma dona de casa pacata disposta a resolver os problemas da família, os filhos são crianças obedientes que, sem exceção, adoram ir para a escola, e o pai, correspondendo à visão patriarcal, é o provedor do lar. Sempre que algum problema surge, ele é logo resolvido e a harmonia é recuperada de imediato. As situações por que passam essas personagens são rasas e não há uma continuidade entre as narrativas, que muitas vezes servem apenas como pretexto para trabalhar algum aspecto gramatical.

Encontram-se, ainda, segundo Janzen (2012), livros em que os personagens são tão fragmentados e metonímicos que não têm nem nome, transcendendo até mesmo o caráter de personagens "planos" para serem meras caricaturas que apenas ilustram vocábulos e/ou estruturas gramaticais. Desaparecendo tão repentinamente como apareceram, podemos dizer que esses personagens metonímicos figuram apenas como ilustração e pretexto para atividades, de modo que não possibilitam a apreensão do Outro da cultura estrangeira, que é totalmente objetificado e cujos diálogos não ser críveis.

Espera-se que o aluno veja tudo isso como verossímil, isto é, que tome aquelas personagens e as situações em que vivem, assim como a própria língua, como representativas da outra cultura. No entanto, sabemos que a outra cultura é formada por muitas vozes. Vozes que o livro didático muitas vezes não permite que sejam ouvidas. Dessa forma, há achatamento do Outro e da outra cultura, e o consequente achatamento da exotopia, de modo que não se permite que o Outro - o estrangeiro ou personagem do livro didático - participe da constituição da identidade do aluno de língua estrangeira, considerando que

\footnotetext{
a percepção, o foco avaliativo, o ponto de observação valorativo-emotivo do outro impregnam a nossa visão de mundo nas primeiras experiências que temos na vida e nos oferecem parâmetros para a construção da nossa Weltanschauung [visão de mundo]. Para Bakhtin, essa orientação axiológica do outro nos acompanha pela vida (JANZEN, 2008, p. 70).
}

Dessa forma, a percepção do estudante da língua estrangeira sobre o(s) Outro(s) da língua-cultura-alvo, a partir de sua representação dentro do livro didático inscrito em propostas de orientação tradicionais e estruturalistas, não permite que ele se construa a partir do olhar do Outro, nem que crie novos sentidos para os textos e enunciados da cultura estrangeira. Além do bloqueio da exotopia e da polifonia na concepção 
tradicional, há duplicação dos valores dos autores e personagens, e o aluno pode acabar mimetizando os personagens em sua previsibilidade e senso comum quando convidado a participar do enredo do livro (JANZEN, 2012), além da reprodução de estereótipos da visão monolítica de cultura e valores do sistema dominante.

Em contrapartida, podemos dizer que na perspectiva da abordagem intercultural apresentadas por Telma Gimenez (2001), ao considerar que língua é cultura, portanto língua-cultura, e explorar um espaço intermediário entre a língua-cultura nativa do aluno e a língua-cultura do Outro, acaba com a prescrição de fatos culturais e abre espaço para que mais vozes adentrem a sala de aula e que vozes híbridas sejam formadas. É importante a presença de várias vozes e de vários Outros autênticos para manter a verossimilhança literária e a verossimilhança da aula, conectando o mundo real - da cultura do aluno e da cultura do Outro - com o mundo da aula, onde a língua é ficcionalizada, de modo a revelar sociedades plurilinguais e multiculturais (JANZEN, 2008).

A partir da comparação entre culturas, a abordagem intercultural possibilita que recuperemos os conceitos bakhtinianos de "polifonia" e "exotopia" para dentro da aula de língua estrangeira ao tratarmos das relações entre aluno, professor, processo de aprendizagem, livro didático, língua e cultura. Podemos analisar ambos os conceitos a partir da constituição dos enunciados e da concepção de língua e cultura dentro da sala de aula, pois cada enunciado carrega em si ressonâncias de outros enunciados já ditos e que ainda serão ditos pelo mesmo locutor ou por outro (BAKHTIN, 1997), e a interculturalidade permite que esses enunciados sejam aproximados e que deles sejam produzidos novos significados.

A sala de aula de língua estrangeira se torna polifônica ${ }^{6}$ ao abrir espaço para mais vozes, seja das culturas da língua materna, seja das culturas da língua estrangeira, seja para o encontro entre elas. A identidade do aluno é constantemente reformulada a partir do contato com a língua-cultura do Outro, que o faz repensar sua visão de mundo e a si mesmo. Podemos dizer que a aula de língua estrangeira é um espaço para ser perpassado pelo dialogismo, seja entre o aluno e o professor, ou entre o aluno e o material didático, e entre o aluno e a língua, considerando que língua e cultura são

\footnotetext{
${ }^{6}$ A especulação acerca da polifonia dentro da sala de aula, que merece ser investigada em diversos contextos de ensino de língua estrangeira, assim como de língua materna, é, aqui, minha especulação (a partir da minha experiência discente e docente).
} 
indissociáveis, de modo a abordar outra(s) visão(ões) de mundo que o ajude(m) a pensar a sua própria visão de mundo (GIMENEZ, 2002).

Sendo um dos elementos que guiam o trabalho na aula de língua estrangeira, o livro didático também precisa ser polifônico nas suas representações da cultura estrangeira, possibilitando que o diálogo intercultural aconteça entre as culturas de modo a não acabar em um diálogo entre "a minha cultura nativa" e uma "cultura idealizada", imprimindo realismo formal na aula. O aluno de língua estrangeira precisa ter contato com várias vozes da outra cultura para que possa construir novas vozes, híbridas e habitantes de um espaço intermediário (GIMENEZ, 2002). É apenas a partir do contato com diversas vozes é que o estudante pode, exotopicamente, remodelar sua própria identidade e construir identidades híbridas.

\section{A LÍNGUA ESTRANGEIRA NA SALA DE AULA}

Podemos especular que outro ponto no qual o realismo formal pode ser comprometido dentro da sala de aula de língua estrangeira é a própria abordagem da língua, seja através das estruturas da língua ensinadas pelo professor ou pelas falas das personagens (JANZEN, 2012). As pessoas comumente falam o inglês da sala de aula de língua estrangeira de modo diferente do inglês falado nos contextos autênticos de prática da língua. Isso acontece porque a sala de aula é, muitas vezes, tratada como um lugar idealizado onde a língua, ainda dentro da abordagem estruturalista, é ensinada estreitamente com base na gramática normativa (SILVEIRA, 1999). Podemos dizer que a quebra da verossimilhança entre mundo real/sala de aula, como ler um diálogo de um romance e pensar, em certos contextos, se considerarmos o realismo formal: "ninguém diria isto", perpassa as estruturas ensinadas no livro didático, os exercícios gramaticais e a própria concepção de língua. É claro que precisamos concordar que a sala de aula é um recorte do mundo real, um local idealizado - um safe place - onde o aluno pode aprender a língua passo a passo, porque é um contexto específico e deslocado espacialmente do local da língua-cultura do Outro. Contudo, isso não impede que várias vozes habitem aquele espaço, além da voz do author team, como já apontado por Janzen (2012), e dos grupos e ideologias dominantes.

\footnotetext{
${ }^{7}$ É válido apontar que algo que jamais seria dito hoje pode já ter sido dito em outro espaço-tempo, pois a língua e o contexto mudam ao longo do tempo, de modo que a concepção de verossimilhança modifica ao longo da história.
} 
REVISTA X, Curitiba, volume 13, n.2, p.93-110, 2018.

Além disso, a presença de exercícios linguísticos descontextualizados que prezam pela repetição mecânica de estruturas é ineficiente, pois a estrutura verbal não é autossuficiente, mas depende de uma situação extraverbal, de modo que cada enunciado precisa de um contexto. A parte extraverbal se cola ao enunciado de modo a fazer parte da estrutura da significação (BAKHTIN; VOLOSHINOV, 2010), pois a palavra carrega em si um conteúdo e uma ideologia ou vivência (BAKHITIN, 2006). Por exemplo, imaginemos a seguinte sentença escrita no quadro negro de uma sala de aula ou impressa em algum livro didático "Mary is eating an apple", e nos perguntemos: quem é Mary? Por que Mary e não Maria? Por que ela está comendo uma maçã? Por que uma maçã e não uma banana?

Exercícios que propõem o preenchimento de lacunas ou a transformação de frases afirmativas para interrogativas seguem a mesma lógica: se não há um contexto para a produção, não há significação completa e, logo, há menos aprendizado. Por exemplo, passar a frase mencionada acima para a interrogativa e para a negativa - Is Mary eating an apple?/ Mary is not eating an apple - continua não respondendo as questões propostas. Nestes casos, a descontextualização achata a língua e a desvincula da cultura. O locutor usa a língua para fins concretos de comunicação, de modo que "enquanto uma forma linguística for apenas um sinal e for percebida apenas como tal, ela não terá para ele nenhum valor linguístico" (BAKHITIN, 2006, p. 94). Além disso, como defende Bakhtin (2006), o sistema linguístico não é um sistema de normas imutáveis, mas apresenta evolução ininterrupta das normas e "o essencial na tarefa de descodificação não consiste em reconhecer a forma utilizada, mas compreendê-la num contexto concreto preciso, compreender sua significação numa enunciação particular" (BAKHTIN, 2006, p. 93).

A compreensão da palavra estrangeira significa deixar-se perpassar pelo Outro através da alteridade e do estranhamento. Além disso, como disse Bakhtin (1997, p. 282): "a língua penetra na vida através dos enunciados concretos que a realizam, e é também através dos enunciados concretos que a vida penetra na língua”. Assim sendo, para a experiência da língua estrangeira dentro da sala de aula ser verossímil, precisamos de um ensino contextualizado e significativo para o aluno em que se tome a língua como viva e mutável, pois, como no romance, a língua é essencial para a construção da realidade e da interação na dinâmica da vida.

A partir da língua e seus enunciados, o aluno de língua estrangeira precisa ter contato com várias vozes da outra cultura para que possa construir novas vozes - 
REVISTA X, Curitiba, volume 13, n.2,p.93-110, 2018.

híbridas e habitantes de um espaço intermediário (GIMENEZ, 2001) - através do contato com as suas próprias vozes. O livro didático muitas vezes acaba por fazer com que o aluno reproduza a voz monolítica do author team e mimetize os diálogos dos personagens.

O uso de materiais autênticos, enquanto materiais reais deslocados de seu contexto para o espaço da sala de aula - análogo ao fato de personagens da ficção serem inspirados em características de pessoas reais - é uma forma de trazer realismo formal e, consequentemente, verossimilhança para dentro da sala de aula, pois aquelas vozes não estão preocupadas em usar as estruturas linguísticas congeladas pela gramática normativa, mas são proferidas por um alguém individualizado que quer comunicar algo dentro de um contexto. É papel do professor enquanto personagem-sujeito, ou até mesmo narrador - já que guia o aprendizado dos leitores-alunos dentro do espaço-tempo da aula -, dar espaço a vozes de personagens que aparentar ser reais dentro da sala de aula e tomar os alunos como sujeitos ativos no processo de construção do conhecimento.

\section{DOIS EXEMPLOS DE REALISMO FORMAL EM MATERIAIS DIDÁTICOS DE LÍNGUA INGLESA}

Para exemplificar a presença de realismo formal, tanto na construção de personagens quanto no uso da língua, serão comparadas brevemente duas propostas acerca da temática Routine (rotina): uma atividade intitulada Daily Routine da seção Vocabulary Bank ${ }^{8}$, do livro New English File, da Cambridge (OXENDEN; LATHANKOENIG; SELIGSON, 2005), e duas atividades da Unidade Temática Routines: Part 1 - the routine of na undergraduate (ANEXO 1, p. 14), criada pela estudante de Letras Tavany Leslei Martins Matoso (UFPR), em 2016, no contexto das disciplinas de Metodologia e Prática de Docência de Línguas Estrangeiras Modernas Anglo-saxônicas, da graduação em Letras da UFPR.

Na primeira atividade, do livro da Cambridge, há uma lista de vinte verbos ao lado de vinte quadros nos quais a rotina da personagem-caricatura Vicky é descrita. $\mathrm{O}$ objetivo é que o aluno relacione os verbos com os quadros. Em seguida, propõe-se que os alunos descrevam, em pares, a rotina de Vicky partindo das figuras. No entanto, o aluno não sabe quem é Vicky, nem saberá, pois ela aparece apenas neste momento (terceira unidade do livro) e desaparece assim que a atividade acaba. Ela só é uma 
REVISTA X, Curitiba, volume 13, n.2,p.93-110, 2018.

personagem particularizada por possuir um nome. Não é possível saber a cultura e a língua de origem dela.

Além disso, Vicky tem uma rotina tão atarefada e idealizada que o dia dela parece extrapolar as vinte e quatro horas diárias e, apesar disso, em nenhum momento a harmonia é rompida, o que quebra a verossimilhança com uma "rotina crível". Dessa forma, Vicky não passa de um pretexto para que os verbos comumente usados para falar de rotinas (get dressed, get up, wake up, etc.) apareçam no livro. Ela também não é o sujeito das estruturas linguísticas, já que os verbos são colocados no infinitivo de forma descontextualizada. Não há polifonia nem exotopia aqui, pois Vicky não permite que o aluno se "imagine" ou se "acabe" sob o olhar dela, nem a integre em seu discurso, nem que realize um diálogo intercultural entre as rotinas de ambos, Vicky e o aluno.

Em contrapartida, a unidade de Tavany Leslei Martins Matoso, produzida para alunos universitários do Idiomas para Fins Acadêmicos (IFA) ${ }^{9}$, da UFPR, apresenta a própria autora como personagem, ou seja, Tavany ficcionaliza sua rotina no material didático, de modo que a personagem do material didático, considerando as formas de criação de seres ficcionais apontadas por Candido (1976), é inspirada em uma pessoa real $^{10}$. O ambiente das fotos e a quantidade de tarefas apresentadas são verossímeis e têm a aparência ou o efeito do real, não necessariamente ser real - não importa se, de fato, a rotina de Tavany é aquela, mas importa aquela rotina parece crível. Por isso, a rotina de Matoso não é idealizada como a de Vicky, e carrega verossimilhança com a vida do estudante, que pega ônibus, almoça "marmita" no trabalho, etc. O aluno consegue ver a realidade do contexto socioeconômico da estudante pelo plano de fundo das fotos, de modo que conseguem traçar a imagem da personagem Tavany e conhecêla (mesmo que superficialmente) e identificar se com a vida dela, que é "verossímil" e "parecida" com a vida de uma estudante universitária brasileira, que é o público-alvo do material. Diferente de Vicky, de quem não se sabe nada, o aluno é informado que "Tavany is an undergraduate student in Letters (sic) - English at UFPR".

Em um primeiro momento, pede-se que o aluno organize a ordem certa de sentenças referentes às imagens que compõem a rotina de Tavany - cada enunciado é contextualizado e apresenta claramente a comunicação/interação entre os interlocutores

\footnotetext{
${ }^{8}$ Não anexamos a imagem da atividade para resguardar os direitos autorais do material didático.

${ }^{9}$ Para mais informações: <www.facebook.com/search/top/?q=idiomas\%20para\%20fins\%20acad\%C3\% AAmicos> Acesso em: 14 abr. 2017.

${ }^{10}$ Mas é importante ressaltar que não corresponde a ela, pois, ao se colocar no material, Tavany desloca sua vida para a ficção e passa a ser personagem cuja vida será lida-escrita pelos leitores.
} 
(Tavany e aluno), e a personagem figura como sujeito nos enunciados. Em um segundo momento, pede-se que o aluno faça uma lista das atividades da rotina de Tavany que também estão presentes em sua rotina - de modo a recuperar a relação existente entre leitor e personagens do romance ["Read again Tavany's routine and make a list with the activities that are also present in your routine”]. Desse modo, o Outro - a personagem inspirada na autora do material, neste caso - ajuda o aluno a completar sua tarefa em uma relação dialógica acerca de rotinas de estudante. A proposta de Tavany traz a realidade para dentro da sala de aula, imprimindo verossimilhança no trabalho com a temática, na construção de personagens e no diálogo intercultural, e trazendo práticas contextualizadas de uso da língua. O Outro que figura na atividade de Matoso é uma personagem brasileira e estudante universitária, com uma rotina próxima à do contexto do público-alvo a que se destina (universitários), de modo que não traz a voz do Outroestrangeiro, mas permite diálogo intercultural entre várias facetas da vida universitária brasileira - inclusive de alunos da mesma universidade -, isto é, permite dialogismo e exotopia, e não duplicação nem mimetização. Além disso, a proposta de Matoso dá espaço para vozes e realidades que comumente não figuram em material didático: um personagem que aparenta ser real - pois, como já apontamos, Tavany deixa de ser uma pessoa ao inscrever sua vida nas imagens e nas frases do material didático, de modo a virar personagem -, o personagem comum que usa a língua viva e mutável em enunciados concretos que visam a interação e a sobrevivência no enredo que é a vida.

\section{O REALISMO FORMAL NA ROTINA DE UMA VIDA FICTO-REAL}

A atividade criada por Matoso acima descrita foi aplicada em uma aula de nível Básico I do projeto Idiomas para Fins Acadêmicos da UFPR, coordenado pela professora Angela Walesko, em 2017, sob a prática docente de Juliana Pedrollo Viani ${ }^{11}$. A aplicação da atividade não apenas mostrou que o tema foi contextualizado na vida dos alunos, mas também que eles motivaram várias habilidades de leitura, de textos escritos - para decodificar o sentido das sentenças em inglês da atividade - e de textos imagéticos.

Os alunos, primeiramente de forma individual, analisaram as fotos para conseguirem realizar o primeiro exercício. Depois, no momento da correção em grupo, discutiram em conjunto os elementos visuais das fotos e chegaram a uma negociação

\footnotetext{
${ }^{11}$ A quem agradeço o consentimento de poder observar sua aula e permitir que eu utilizasse minhas observações e apontamentos neste artigo.
} 
REVISTA X, Curitiba, volume 13, n.2,p.93-110, 2018.

acerca da ordem entre as fotos e também da rotina da personagem. Os alunos apontaram, por exemplo, que ela toma café da manhã na cozinha da escola em que trabalha [foto 2] (muitos alunos haviam ligado esta imagem ao almoço) e, portanto, come depois de andar de bicicleta [foto 4]. Houve uma discussão quanto ao momento em que Tavany estuda, pois alguns não haviam decodificado o sentido da sentença “( ) She wakes up to study at home", de modo que o conhecimento linguístico do grupo ajudou esses alunos a lerem a imagem. Houve quem apontasse o fato de as fotos [1] e [9] serem intercambiáveis na atividade, pois: (i) ela pode chegar à universidade e se dirigir à cantina para comprar um lanche, já que ela saiu do trabalho, pegou o ônibus e pode estar com fome, e depois de alimentada é que se dirige à copiadora, ou (ii) ela chega à universidade e logo tira as cópias para evitar filas e/ou para poder ler o texto enquanto come seu lanche na cantina. Além disso, considerando que todos os alunos da turma são alunos universitários (de cursos de humanas, biológicas e exatas) da UFPR, a professora perguntou quem tinha o hábito de tirar cópias de livros e textos, o que gerou uma breve discussão sobre a carga de leitura das diferentes áreas. A partir disso, a professora contextualizou os advérbios de frequência (always, often, sometimes, usually, seldom, never) dentro da segunda parte da atividade.

$\mathrm{O}$ fato de a atividade, que consistia em relacionar imagens a sentenças, não ter uma resposta certa e verdadeira, mas ter uma resposta construída, mostra que as narrativas e as leituras são individuais e que podem ser negociadas e socializadas, como aconteceu com a foto [5]. A atividade, ao ser colocada em prática, não apenas nos mostrou que Tavany, enquanto personagem - homo fictus -, é uma personagem redonda e complexa, cuja vida permite várias leituras e permite a criação de várias narrativas. Cada aluno, enquanto leitor que tem uma narrativa de vida, deu a Tavany um acabamento (exotópico) diferente e, a partir da rotina da personagem, pôde repensar e construir sua própria rotina em língua inglesa, ressignificando as palavras de modo contextualizado. Considerando que Tavany é uma "pessoa real" deslocada para o material didático, podemos também apontar que o real depende da percepção de realidade de quem está lendo este real ficcionalizado no material didático, assim como o romance pode ser definido como real ficcionalizado. Considerando o contexto, a realidade de Tavany e sua rotina dependem da percepção do real dos personagens que habitam o espaço da sala de aula, ou seja, alunos e professora. A dinâmica da aula e a utilização do material criado construiriam outras narrativas se fossem em um contexto em que os alunos não compartilhassem de rotinas semelhantes à de Tavany. Em uma 
aula de inglês no Ensino Médio, por exemplo, talvez a rotina de Tavany comprovasse ou mostraria um contraponto para a fantasia dos alunos acerca da vida de um universitário. Em uma aula de inglês para estudantes universitários de outro país, a língua inglesa seria a mediadora do diálogo intercultural entre a cultura do aluno e a cultura brasileira. Em suma, podemos dizer que a verossimilhança e o realismo formal da atividade acontecem na relação entre todos estes personagens, a língua, o espaço e a vida em si.

\section{CONSIDERAÇÕES FINAIS}

A sala de aula de língua estrangeira é um espaço para ser perpassado pelo dialogismo, seja entre o aluno e o professor, ou entre o aluno e o material didático, ou entre o aluno e a própria língua, considerando que língua e cultura são indissociáveis (GIMENEZ, 2001). A forma como a língua e a cultura são concebidas no espaço da aula e a forma com o Outro estrangeiro é representado influencia na agência e na verossimilhança do tratamento da língua e no diálogo intercultural entre língua-cultura materna e língua-cultura estrangeira. Assim como o personagem depende do olhar do(s) Outro(s), isto é, do narrador/autor/leitor, para se constituir e, considerando seu fechamento dentro do espaço do romance, para existir, o aluno de língua estrangeira precisa do olhar do Outro para se constituir e criar um diálogo entre a sua língua-cultura materna e a língua-cultura do Outro. Para tal, é importante que a língua seja contextualizada e viva, e que o material didático apresente verossimilhança na figura de suas personagens e seja contextualizado de modo que o aluno consiga realizar a exotopia e que o Outro consiga ajudá-lo a dar acabamento à sua incompletude e mostrar-lhe outra visão de mundo, e que essa outra visão de mundo o ajude a pensar a sua própria visão de mundo (GIMENEZ, 2001). Para tal, a dinâmica ficcional da sala de aula de língua estrangeira precisa ser crível, isto é, que a língua e a cultura sejam realistas e não achatadas, tentem mostrar relatos autênticos humanos do(s) Outro(s) desconhecido(s), revelando e construindo novas comunidades multiculturais e multilinguais. $\mathrm{O}$ estudante tem, então, a possibilidade de ver o mundo a partir do olhar do Outro, e também de, após perceber o mundo através de outra perspectiva, voltar à sua posição inicial e reformular a sua visão de mundo, linguística e culturalmente. 


\section{REFERÊNCIAS}

BAKHTIN, Mikhail; VOLOSHINOV, Valentin. Discurso na vida e discurso na arte: sobre poética sociológica. Trad. Carlos Alberto Faraco; Cristovão Tezza. 2010 [1926].

. A Estética da Criação Verbal. São Paulo: Martins Fontes, 1997.

. "Língua, fala e enunciação". In Marxismo e filosofia da linguagem.

São Paulo: HUCITEC, 2006.

CANDIDO, Antonio. "A personagem do romance". In (Org.). A Personagem de ficção. São Paulo: Perspectiva, 1976, pp. 53-78.

FREIRE, Paulo. Pedagogia da Autonomia. São Paulo: Paz e Terra, 1996.

GIMENEZ, Telma. "Eles comem cornflakes, nós comemos pão com manteiga": espaços para reflexão sobre cultura na aula de língua estrangeira. IX Encontro de Professores de Linguas Estrangeiras, 2002, Londrina. Anais do IX EPLE. Londrina: APLIEPAR, 2001, pp. 107-114.

ISER, Wolfgang. O ato da leitura (vol. 1 e 2) São Paulo: Editora 34, 1996.

JANZEN, Henrique Evaldo. Concepções de cultura e o ensino de línguas estrangeiras modernas. In SCHMIDIT, Maria Auxiliadora; GARCIA, Tânia Maria F. Braga; HORN, Geraldo Balduíno (Org.). Diálogos e perspectivas de investigação. Ijuí: UNIJUÍ, 2008, pp. 63-76.

A Alteridade: um olhar intercultural. In STOLTZ, Tânia; GUERIOS, E. (Org.). Educação e Alteridade. São Carlos: EdUSCar, 2010, pp. 211-222.

Concepção bakhtiniana de literatura e a análise de personagens nos livros didáticos de LEM. Bakhtiniana. São Paulo, 7 (1), jan/jun, 2012, pp. 107-124.

KUNDERA, Milan. A arte do romance. São Paulo: Companhia das Letras, 2009.

MATOSO, Tavany Leslei Matoso. Routines. Curitiba: UFPR, 2016 (material didático produzido para o projeto Idioma para Fins Acadêmicos).

OXENDEN, Clive; LATHAN-KOENIG, Christina; SELIGSON, Paul. New English File. Oxford/New York: Oxford University Press, 2005.

SILVEIRA, Maria I. M. Línguas Estrangeiras: uma visão histórica das abordagens, métodos e técnicas de ensino. Maceió - São Paulo: Edições Catavento, 1999.

TEZZA, Cristovão. A construção das vozes no romance. (Colóquio Internacional Dialogismo: Cem Anos de Bakhtin'). In BRAIT, Beth (org.). Bakhtin, dialogismo e construção do sentido. Campinas: Editora da Unicamp, 2001. Disponível em: $<\mathrm{http}: / /$ www.cristovaotezza.com.br/textos/palestras/p_vozesromance.htm>. Acesso em: 08 nov. 2016. 
WATT, Ian. O realismo e a forma do romance. In A ascensão do romance. São

Paulo: Companhia das Letras, 1990, pp. 11-33. 


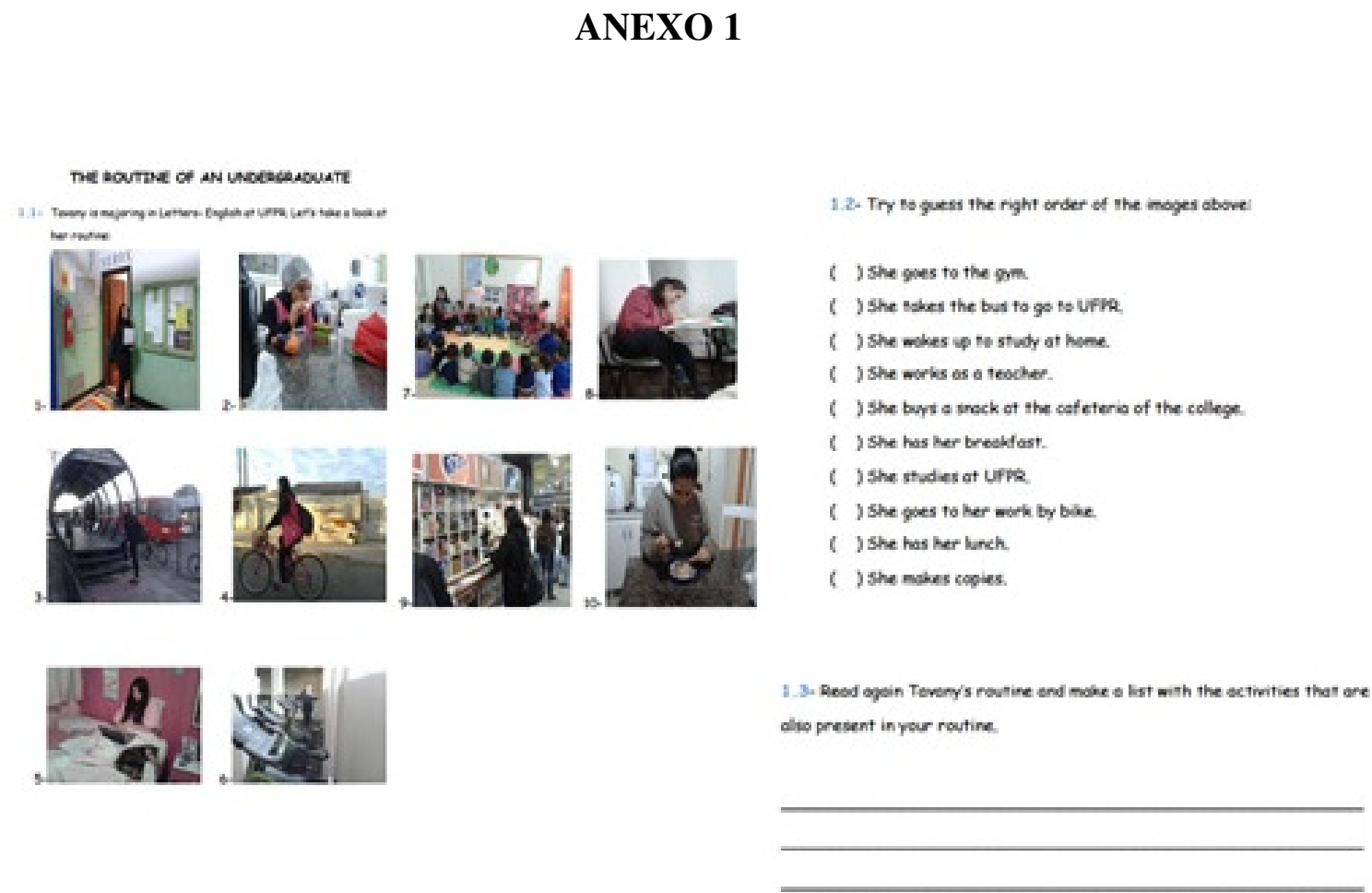

Fonte da imagem: Unidade Temática criada por Tavany Leslei Martins Matoso para a disciplina de "Metodologia do Ensino de LEM Anglo-saxônica" (EM115), do curso de Letras da Universidade Federal do Paraná (UFPR), sob orientação do Prof. ${ }^{\circ}$ Dr. Henrique Evaldo Janzen, em 2016. 